\title{
Turismo responsável e eventos: uma análise sobre a responsabilidade no Festival Internacional de Cinema e Video Ambiental (FICA) - Goiás/GO
}

\begin{abstract}
Responsible tourism and events: an analysis on responsibility at the international Festival of Cinema and Environmental Video (FICA) - Goiás / GO
\end{abstract}

Turismo responsable y eventos: un análisis sobre la responsabilidad en el Festival Internacional de Cinema y Video Ambiental (FICA) - Goiás / GO

\section{Donária Coelho Duarte ${ }^{1}$ Kezya Silva Coelho Lima}

Resumo: Diante das discussões sobre responsabilidade e do seu papel no turismo, o presente trabalho propõe analisar de que forma as dimensões do Turismo Responsável podem contribuir para o planejamento, realização e gestão da realização de eventos. Entende-se que este trabalho contribui com a área de turismo devido a escassa literatura que aborde os eventos numa perspectiva da responsabilidade. Para essa análise é tomado como objeto de estudo o XVIII Festival Internacional de Cinema e Vídeo Ambiental (FICA) que acontece no município de Goiás/GO. A pesquisa caracteriza-se como qualitativa e exploratória, utilizando-se de levantamento bibliográfico e documental, observação e entrevistas aplicadas aos visitantes/participantes e gestores do Evento. Foi possível constatar que o FICA realiza algumas ações voltadas para a responsabilidade, entre elas destaca-se a busca pelo envolvimento da comunidade local, mas não pode ser considerado um Evento totalmente responsável. Constatou-se que o mesmo não aplica as três dimensões da responsabilidade e utiliza-se do termo apenas como forma de divulgação.

Palavras chave: Turismo. Eventos. Turismo Responsável. Sustentabilidade.

Resumen: Ante las discusiones sobre responsabilidad y su papel en el turismo, el presente trabajo se propone analizar cómo las dimensiones del Turismo Responsable pueden contribuir a la planificación, realización y gestión de la realización de eventos. Se entiende que este trabajo contribuye con el área de turismo debido a la escasa literatura que aborde los eventos desde una perspectiva de la responsabilidad. Para este análisis se toma como objeto de estudio el XVIII Festival Internacional de Cine y Vídeo Ambiental (FICA) que se realiza en el municipio de Goiás/GO. La investigación se caracteriza como cualitativa y exploratoria, utilizando el levantamiento bibliográfico y documental, observación y entrevistas aplicadas a los visitantes/participantes y gestores del Evento. Es posible constatar que el FICA realiza algunas acciones dirigidas a la responsabilidad, entre ellas se destaca la búsqueda por la participación de la comunidad local, pero no puede ser considerado un Evento totalmente responsable. Se constató que el mismo no aplica las tres dimensiones de la responsabilidad y se utiliza del término sólo como forma de divulgación.

Palabras clave: Turismo. Eventos. Turismo Responsable. Sostenibilidad.

\footnotetext{
${ }^{1}$ Professora Adjunta da Universidade de Brasília onde leciona na graduação no Curso Gestão de Agronegócios Membro do Laboratório de Estudos de Turismo e Sustentabilidade (Lets/UnB) e do Grupo de Pesquisa Produção, Consumo, Turismo e Sustentabilidade. Coordena o Núcleo de Estudos sobre Turismo Responsável, Acessível e Sênior (Netras - All). E-mail: http://orcid.org/0000-00017673-0227 Orcid: http://orcid.org/0000-0001-7673-0227

${ }^{2}$ Mestre em Turismo (CET/UnB), Especialista em Gestão de Empreendimentos Turísticos e Eventos (2014). Atua na área de eventos em empresa privada e como consultora para realização de eventos principalmente com foco em sustentabilidade. E-mail: kezya.c.lima@gmail.com Orcid: http://orcid.org/0000-0003-3775-3893
} 
Abstract: In the face of discussions about responsibility and yours role of tourism, this paper proposes to analyze how the dimensions of Responsible Tourism can contribute to the planning, realization and management of events. It is understood that this work contributes to the tourism are due to the lack of literature that adresses the events from a responsability perspective. For this analysis is taken as object of study the XVIII International Festival of Environmental Film and Video (FICA) that happens in the city of Goiás/GO. The research is characterized as qualitative and exploratory, using the bibliographic and documentary survey, observation and interviews applied to the visitors/participants and managers of the Event. It was possible to verify that the FICA performs some actions directed to the responsability, among them the search for the involvement of the local community, but it can't be considered a totally responsible Event. I was found that it doesn't apply to the three dimensions of responsabilty and uses the term only as a form of disclosure.

Keywords: Tourism. Events. Responsible Tourism. Sustainability.

\section{Introdução}

Diante das possibilidades de esgotamento de recursos naturais, tratar da sustentabilidade tornou-se uma necessidade. Nesse sentido, diversos segmentos do mercado incluíram em sua pauta de discussões este assunto buscando ações que possam minimizar o impacto causado por sua atuação.

É necessário compreender que a sustentabilidade não se refere apenas ao aspecto de preservação e conservação ambiental. Ela considera e deve abarcar os aspectos socioculturais e econômicos para que de fato seja efetiva. Essa compreensão configura-se como um desafio para os diversos setores envolvidos no desenvolvimento da atividade e do fenômeno que é o Turismo.

Por razões como essas, os Eventos começaram a ser valorizados dentro do contexto do Turismo Nacional tendo sido mencionados como segmento pelo Ministério do Turismo (Turismo de Negócios e Eventos). Além disso, a busca por eventos internacionais para o calendário nacional como a Jornada Mundial da Juventude em 2013 e a Copa do Mundo em 2014 evidenciaram a importância do segmento para o desenvolvimento da atividade turística no país.

Diante de um cenário de crescentes discussões sobre sustentabilidade, a responsabilidade em Turismo e a realização de eventos, torna-se necessário discussões que conduzam a uma atuação prática. Tal abordagem consiste em aplicar conceitos de responsabilidade ao planejamento e execução de Eventos, aferindo a efetividade de ações. Assim, trata-se de não apenas indicar ações possíveis e já realizadas, mas sim diz respeito a busca de aferir a sua efetividade. Neste sentido, entende-se que este trabalho contribui com a área de turismo devido a escassa literatura que aborde os Eventos numa perspectiva da responsabilidade. 
Sob este aspecto, ressalta-se que a responsabilidade não pode se tornar uma utopia e algo inalcançável por parte dos produtores e organizadores de Eventos. É necessário apontar maneiras práticas possíveis, com o propósito de cada vez mais migrar as teorias do campo teórico para uma prática consciente e que gere resultado. Desse modo é possível aprimorar os mecanismos adotados, repetindo assim as boas práticas e realizando os ajustes necessários para tornar o objetivo concreto.

Neste sentido, o objetivo deste artigo é analisar até que ponto o XVIIII Festival Internacional de Cinema e Vìdeo Ambiental (FICA) apresenta prática de responsabilidade a partir da percepção de seus visitantes/participantes e gestores. O FICA é um festival de cinema que acontece na Cidade de Goiás há 18 anos. Desse modo, a edição do evento que é analisada é sua décima oitava edição que aconteceu no ano de 2016. A cidade de Goiás é uma cidade do interior do Estado de Goiás que é conhecida por ser Patrimônio Cultural Mundial, reconhecida assim pela Unesco no ano de 2001 (Bottallo, 2014).

Considerando FICA como um festival de cinema internacional, acredita-se que este Evento também possa ter práticas de responsabilidade. Além disso, a cidade onde ele ocorre é considerada Patrimônio Cultural Mundial, o que eleva a preocupação com sua preservação e torna as práticas responsáveis indispensáveis nas ações de planejamento de qualquer atividade que venha ocorrer na cidade. Realizando a análise do Evento na perspectiva da responsabilidade, é possível auxiliar na elaboração e condução de futuras ações responsáveis para o mesmo.

\section{O turismo responsável e o turismo de eventos}

Numa sociedade em que a produção e o consumo são realizados pensando apenas nos interesses individuais, não se preocupando com o bem comum e considerando que nossos recursos são finitos, é natural que surjam problemas decorrentes desse modelo de produção e consumo (Hardin, 1968).

O crescimento do Turismo tem levantado diversas questões sobre a sua sustentabilidade. É importante reconhecer o impacto ambiental gerado por ele e a limitada importância dada ao desenvolvimento de comunidades locais a partir do turismo (Cape Town, 2002).

Sob este aspecto, Ramoa, Flores e Stecker (2018) enfatizam que o tema da sustentabilidade é amplo e causa muita discussão, inclusive na indústria do turismo. Os autores consideram que vários setores da economia exigem estratégias que, além do lucro, focam também aspectos socioculturais e ambientais, visando alcançar crescimento e 
desenvolvimento sustentável para atender aos desejos das gerações atuais e futuras com uma melhor qualidade de vida.

Nesse contexto, o Turismo Responsável (TR) surge como alternativa e, porque não, ampliação do discurso sobre a sustentabilidade. Busca encontrar formas práticas para esse fim. Para abordar o TR deve-se, em primeiro lugar, fazer uma reflexão sobre o que de fato é essa responsabilidade. Questionar até que ponto se tem pensado na responsabilidade das ações tomadas para o desenvolvimento do turismo é um dos primeiros questionamentos que vem a mente quando deparamos com a terminologia TR.

Leslie (2012) destaca que se utilizamos o termo responsável, isso implica em 'responsável por' e deve ser aplicado nas consequências do Turismo. A responsabilidade é facilmente aplicada em diversas áreas e não somente no turismo e a utilização dela leva a pensar que isso se deve justamente a observação de atitudes não responsáveis no turismo (Leslie, 2012).

Desse modo, infere-se que é sobre essas consequências que se refere essa responsabilidade. Sendo essas consequências provenientes da atividade turística, tal responsabilidade não se limita a um ou outro segmento específico do Turismo, mas tudo e todos que estão envolvidos no processo da atividade e no fenômeno que é o Turismo.

Na 6a Conferência Internacional de Turismo Responsável nos Destinos que ocorreu em 2012, Goodwin reforçou as principais características do Turismo Responsável, características que também foram consideradas na Declaração de Cape Town. São elas:

(1) minimiza impactos econômicos, ambientais e sociais negativos, (2) gera maiores benefícios econômicos para população local e melhora o bem-estar das comunidades de acolhimento, melhora as condições de trabalho e acesso à indústria, (3) envolve a população local nas decisões que afetam suas vidas e oportunidades de vida, (4) faz contribuições positivas para a conservação do patrimônio natural e cultural, para a manutenção da diversidade (5) proporciona experiências mais agradáveis para os turistas através de conexões mais significativas com as pessoas locais, e promove uma maior compreensão das questões culturais, sociais e ambientais da localidade, (6) fornece acesso para as pessoas portadoras de deficiência; (7) é culturalmente sensível, gera respeito entre turistas e anfitriões, e constrói o orgulho local e confiança. (Goodwin, 2012, p. 399-400, tradução nossa).

Enfatiza-se, portanto, que o TR não se propõe como um segmento ou tipo de Turismo, limitado a um determinado mercado. Ele se propõe como um agente de mudança, um catalizador do desenvolvimento regional através da inclusão social, valorização da cultura local e conservação e preservação do ambiente natural.

Compreendendo os Eventos como parte do Turismo, buscou-se a aplicação dos princípios do TR no setor. Leslie (2012) ressalta que a responsabilidade é um comportamento que pode ser igualmente aplicado em qualquer negócio. Desse modo, é 
possível considerar as premissas da responsabilidade também no setor de Eventos inserido no Turismo.

Especificamente na dimensão cultural, Macedo, Gosling e Queiroz (2017) corroboram com a temática ressaltando a importância dos Eventos como ferramentas para a manifestação da cultura, já que eventos culturais ainda são privilégio de uma minoria na medida em que o seu acesso está relacionado ao capital financeiro e intelectual do indivíduo.

Já na vertente ambiental, Pereira e Conto (2008) consideram que um Evento turístico tem características de uma pequena empresa com operações bem definidas, na medida em que consome energia, água e outros recursos, gerando resíduos sólidos, emissão de gases e efluentes líquidos. Portanto, os Eventos possuem uma grande responsabilidade na preservação ambiental.

A fim de organizar os processos de planejamento e organização dos Eventos, Matias (2013) cita três períodos distintos de planejamento. São esses períodos: Pré-evento, Transevento, Pós-evento.

O período do Pré-evento corresponde as atividades necessárias para o planejamento do Evento que ocorrem antes da data de sua realização. Esse período compreende a concepção do evento, definição de tema e dos seus objetivos, escolha de data e local, inscrições e vendas de ingressos, realização de orçamentos, montagem da estrutura necessária e todas as atividades e tarefas necessárias de planejamento para que o Evento aconteça e seja bem sucedido.

O Transevento trata da realização do evento em si. É o dia e o momento em que ele acontece. É nesse estágio que o participante vivencia a experiência e tem contato com o que foi planejado e elaborado no pré-evento. Complementando esta etapa, Farias, Zucco e Falaster (2019) consideram que o conjunto de percepções que um indivíduo tem em relação a um evento pode ser interpretado como a imagem dele. Essa imagem só pode ser construída a partir da visita do indivíduo adicionado às associações que ele faz sobre o Evento.

O Pós-evento, por sua vez, é o momento após a realização dele. É nessa etapa que são fechados relatórios e feita avaliação do evento como um todo. Também é realizada a desmontagem do Evento, no caso da necessidade de montar uma estrutura para tal.

Infere-se, portanto, a importância da aplicação dos princípios da responsabilidade em todas as etapas de realização de um Evento, pois desse modo será possível considerar aspectos econômicos, a proteção ambiental, mas também os aspectos socioculturais, esses muitas vezes negligenciados. Entende-se que a falta de uma visão responsável em alguma das etapas para a realização de um Evento, pode comprometê-lo na sua totalidade, 
prejudicando a imagem do mesmo e o seu slogan de "responsabilidade". Assim, deve-se considerar os valores sociais da localidade e fechar o ciclo da responsabilidade nas dimensões que esse contempla.

Discutindo as questões da responsabilidade em Eventos, destaca-se que se trata de 'tentar', evidenciando assim o desafio para a responsabilidade no setor. Sob este aspecto, Silberberg e Dowell (2010, p. 738) afirmam:

A responsabilidade se dá pelo levantamento, controle e monitoramento dos aspectos e impactos socioambientais que envolvem o evento. A escolha dos limites e a aceitação dos resultados determinarão seu grau de responsabilidade socioambiental. Não é possível pensar em sustentabilidade quando, por exemplo, contratam-se empresas não comprometidas com o atendimento à legislação, com o pagamento de impostos, emissão de notas, registro de funcionários etc. Um evento com alto grau de responsabilidade socioambiental deve refletir sobre todos os seus impactos na cadeia produtiva, incluindo os impactos de seus fornecedores. Devem-se observar, além de seus impactos ambientais diretos, questões como a acessibilidade de deficientes físicos aos locais e seu impacto na comunidade do entorno. (Silberberg \& Dowell, 2010, p. 738).

Essas mesmas autoras mencionam a responsabilidade social e a gestão ambiental como pontos de atenção dentro da organização de Eventos. Chamam a atenção para aspectos como a localização, a importância da escolha de parceiros comprometidos com a sustentabilidade e a responsabilidade social, a utilização de tecnologias limpas, o gerenciamento de resíduos sólidos e outros aspectos importantes da gestão ambiental e responsabilidade social.

Diante do exposto percebe-se que já existe uma preocupação com aspectos de responsabilidade na realização de Eventos, evidenciando assim a necessidade da criação de diretrizes e políticas que orientem essa prática.

\section{Metodologia}

Este trabalho utiliza a pesquisa qualitativa como forma de análise de dados, visto que faz o estudo de uma determinada realidade. Portanto se trata de uma pesquisa exploratória, com abordagem qualitativa. Nesse sentido, a realidade a ser observada é a realidade do Evento escolhido para observação, explorando as possibilidades que poderão ser percebidas nele voltadas para a responsabilidade.

Enquanto técnicas de pesquisa, selecionou-se a bibliográfica, documental e a pesquisa de campo. A técnica de pesquisa bibliográfica foi utilizada com o objetivo de proporcionar familiarização com o tema e construção de um referencial teórico que pudesse delimitar melhor os objetivos. Especificamente a pesquisa documental foi utilizada no resgate de dados sobre edições passadas do Evento em análise. 
Os temas centrais escolhidos para orientar a pesquisa bibliográfica foram Eventos, buscando compreender sua concepção e importância para o Turismo; e o Turismo Responsável, focando na sua importância para o desenvolvimento do Turismo de forma equitativa.

Desse modo foi possível construir um referencial teórico que pudesse conduzir as ações para a pesquisa de campo. Para aprofundar e buscar alcançar os objetivos propostos foi escolhido o XVIII FICA - Festival Internacional de Cinema e Vídeo Ambiental para análise.

O FICA foi escolhido por se tratar de um Evento que demonstra em seu próprio nome a preocupação com questões referentes a sustentabilidade. Desse modo, acredita-se e é esperado que ele busque ações práticas de responsabilidade, permitindo a pesquisa aferir se isso de fato ocorre e como ocorre, o que permite identificar as oportunidades e os desafios para a realização de Eventos responsáveis.

Para complementar os dados da pesquisa foram realizadas entrevistas com pessoas estratégicas com a finalidade de identificar a intenção da responsabilidade e a preocupação com ela na realização do Evento analisado. O objetivo foi realizar entrevistas com dois grupos distintos: os gestões do Evento e seus visitantes/participantes.

Para a entrevista com gestores foi mapeada a pesquisa com quatro pessoas tomando por base as informações dos idealizadores do Evento, conforme disponível no site oficial do mesmo.

Para a pesquisa com os participantes/visitantes do FICA, optou-se pela amostra nãoprobabilística acidental que, segundo Oliveira (2007), permite a seleção de entrevistados de forma assistemática e, conforme a amostra coletada, é determinado o tamanho que ela terá.

Entende-se por visitantes/participantes aqueles que fazem parte do público do FICA, no qual o objetivo foi identificar o seu reconhecimento sobre a responsabilidade no Evento. As entrevistas com esse segmento foram aplicadas ao longo do Evento e totalizaram 17 investigados.

O roteiro de entrevista direcionado aos visitantes/participantes do FICA possuía perguntas abertas. Essas tinham o objetivo de alcançar uma maior profundidade nas respostas e a obtenção de informações que não poderiam ser obtidas com a aplicação de questões fechadas. Desse modo, as respostas foram gravadas e analisadas em momento posterior a realização deste levantamento.

Uma vez de posse dos dados, a análise foi realizada de forma qualitativa objetivando identificar as oportunidades e os desafios para os Eventos Responsáveis (ER) tendo como foco de análise o FICA. Assim foi possível obter os elementos necessários para a resposta 
do objetivo proposto, de forma a identificar as ações do Evento já praticadas e as que seriam possíveis voltadas para a responsabilidade.

\section{Entrevistas com visitantes/participantes do FICA 2016}

As entrevistas com os visitantes/participantes se configuraram um grande desafio visto que muitos não estavam dispostos a concedê-la. Um dos causadores desse fato foi a programação, pois assim que saíam de uma atividade, os participantes já seguiam para outra. Além disso, estavam em um momento de lazer e descontração, o que fez com que muitos não quisessem parar para atender e responder a pesquisa. No entanto, foi possível realizar 17 entrevistas, além de conversas aleatórias durante o Evento que também produziram conteúdo para análise através de anotações realizadas ao longo dos dias. Essas conversas de forma rápida foram uma estratégia para obter informações que possibilitassem a análise, mesmo que não resultassem no preenchimento formal do formulário. Desse modo, tudo isso gerou anotações que foram analisadas posteriormente.

As perguntas direcionadas para os visitantes/participantes foram as seguintes:

$1 \quad \mathrm{O}$ sr(a) acredita que os eventos devem se preocupar com a responsabilidade sociocultural, ambiental e econômica do local onde ele ocorre?

2 Se o $\operatorname{sr}(a)$ sabe que um evento busca ser responsável nas suas práticas isso aumentaria as suas chances de participar dele?

$3 \mathrm{O}$ sr(a) percebe essa preocupação enquanto participa do FICA?

4 Como é possível perceber essa preocupação no FICA?

5 Durante o evento o sr(a) observa a valorização da cultura local da cidade?

6 Durante o evento o $\operatorname{sr}(\mathrm{a})$ observa a preocupação dos realizadores com a preservação do meio ambiente?

7 Na sua opinião o FICA representa a cidade e contribui para sua valorização?

$80 \mathrm{sr}(\mathrm{a})$ considera o FICA um evento responsável socioculturalmente, economicamente e ambientalmente? Por que?

Conforme resultados apresentados nas respostas as Questões 1 e 2, é possível notar que existe uma consciência da necessidade com a realização de ER por parte do público do FICA 2016. Também percebe-se que, se o Evento utiliza essa temática e demonstra se preocupar com ações sustentáveis, isso aumenta as chances de participação no mesmo. Este fato vai ao encontro de outras pesquisas que já evidenciam essa 
preocupação por parte do público comprovando também o modo como essa temática agrega valor a marca e, nesse contexto, ao Evento.

Conforme abordado ao longo desta pesquisa, há relação entre o interesse do público e a utilização de temáticas que envolvam a responsabilidade. Os resultados aqui apresentados corroboram com esse aspecto. Vale ressaltar a importância da utilização desses termos de modo efetivo e não apenas com o intuito de atrair público ou mesmo agregar valor a marca. Nesse sentido, há certa preocupação visto que, ao questionar os organizadores sobre o Evento ser responsável, eles afirmam que este não é o foco, apesar da temática ser centrada na questão ambiental. Isso foi notado pelo público que aponta ações de responsabilidade, mas acreditam que não são suficientes.

Continuando a análise, a Questão 3 mostra que a maioria dos entrevistados (13 de 17 entrevistados), percebe a preocupação que o FICA 2016 tem com a responsabilidade. Segundo os entrevistados, isso é percebido na temática do Evento, na programação, na participação da comunidade, nos banners do Evento, na infraestrutura e na valorização da cultura local. No entanto, apesar de sinalizar essas opções, muitos entrevistados foram críticos ao apontarem que a ação mais sustentável que percebiam era a distribuição de lixeiras pela cidade e entendiam que é necessário mais que isso.

$\mathrm{Na}$ Questão 5 os entrevistados foram questionados sobre a percepção da valorização da cultura local. 11 dos 17 entrevistados informam que sim, é possível perceber essa preocupação. Isso fica evidenciado para os participantes do Evento nos espaços de exposição, nas apresentações regionais. Também foi citada a divulgação do Bioma Cerrado que ocorreu durante várias atividades, como nas oficinas, e o fato de ele ocorrer no Centro Histórico de Goiás que por si só já divulga e valoriza a cultura da Cidade.

Apesar dos respondentes afirmarem que percebem valorização da cultura local, o Evento falha nesse aspecto. Participantes relataram que buscaram informações sobre a Cidade e sua história, no entanto não encontraram. Apesar de alguns museus estarem próximos de espaços onde eram realizadas atividades da programação, não havia divulgação desses locais. Apenas os mais curiosos descobriam os museus. Nesse sentido, infere-se que vale a utilização de informativos, ou mesmo mencionar esses locais entre as exibições dos filmes, ou ainda realizar a criação de um espaço dentro do Evento para a divulgação da história da cidade de Goiás. Nenhuma dessas ações foram identificadas no FICA.

Dando continuidade, na Questão 6 foi diagnosticada que os visitantes/participantes percebem a preocupação dos realizadores com a preservação do meio ambiente. Eles percebem isso na coleta do lixo, no entanto apontaram que ainda há muito o que ser feito e que apenas se preocupar com o lixo não torna o evento responsável. 
Quando questionados sobre se o FICA representa a cidade (Questão 7), os respondentes concordam que sim. Eles afirmam que isso ocorre devido a todas as edições do Evento terem sido realizadas na Cidade de Goiás, mas não necessariamente porque o Evento representa a cidade. Com o amadurecimento do Evento em suas várias edições, começa a criar essa identidade e, tanto visitantes como os moradores, já fazem essa relação da identidade da Cidade de Goiás com o FICA.

O roteiro de entrevista foi finalizado com a Questão 8 na qual diagnosticou-se que 10 visitantes/participantes consideram o FICA como um evento responsável socioculturalmente, economicamente e ambientalmente, entretanto 7 responderam que não 0 consideram. A seguir o Quadro 1 apresenta o resumo das percepções dos respondentes:

Quadro 1: Análise do roteiro de entrevistado aplicado aos visitantes/participantes

\begin{tabular}{|c|c|c|}
\hline \multicolumn{3}{|c|}{ Questionário visitante/participante } \\
\hline Questionamento & Objetivo & Percepções e análise \\
\hline $\begin{array}{l}\text { O sr(a) acredita que eventos } \\
\text { devem se preocupar com a } \\
\text { responsabilidade } \\
\text { sociocultural, ambiental e } \\
\text { econômica do local onde ele } \\
\text { ocorre? }\end{array}$ & $\begin{array}{l}\text { Identificar o valor } \\
\text { percebido pelo } \\
\text { participante sobre } \\
\text { responsabilidade em } \\
\text { eventos. }\end{array}$ & $\begin{array}{l}\text { De modo geral o público valoriza } \\
\text { eventos responsáveis }\end{array}$ \\
\hline $\begin{array}{l}\text { Se o sr(a) sabe que o } \\
\text { Evento busca ser } \\
\text { responsável nas suas } \\
\text { práticas isso aumentaria as } \\
\text { suas chances de participar } \\
\text { dele? }\end{array}$ & $\begin{array}{l}\text { Identificar a percepção do } \\
\text { e o valor agregado pela } \\
\text { responsabilidade na } \\
\text { realização de eventos }\end{array}$ & $\begin{array}{l}\text { Há valorização de eventos } \\
\text { responsáveis e isso pode influenciar } \\
\text { na decisão do participante. No entanto } \\
\text { caso um evento não seja responsável, } \\
\text { isso não impede a participação }\end{array}$ \\
\hline $\begin{array}{l}\text { O sr(a) percebe essa } \\
\text { preocupação enquanto } \\
\text { participa do FICA? }\end{array}$ & $\begin{array}{l}\text { Aferir a percepção do } \\
\text { entrevistado em relação a } \\
\text { responsabilidade no FICA }\end{array}$ & $\begin{array}{l}\text { Algumas ações são percebidas, mas } \\
\text { apontadas como insuficientes. }\end{array}$ \\
\hline $\begin{array}{l}\text { Como é possível perceber } \\
\text { essa preocupação no FICA? }\end{array}$ & $\begin{array}{l}\text { Verificar práticas } \\
\text { responsáveis percebidas } \\
\text { pelo entrevistado }\end{array}$ & $\begin{array}{l}\text { A coleta de lixo é a ação mais } \\
\text { expressiva e percebida pelo público. }\end{array}$ \\
\hline $\begin{array}{l}\text { Durante o Evento o sr(a) } \\
\text { observa a valorização da } \\
\text { cultura local da cidade? }\end{array}$ & $\begin{array}{l}\text { Identificar ações de } \\
\text { valorização da cultura } \\
\text { local no FICA }\end{array}$ & $\begin{array}{l}\text { A valorização da cultura é notada em } \\
\text { espaços de exposição e nas } \\
\text { apresentações de artistas locais. }\end{array}$ \\
\hline $\begin{array}{l}\text { Durante o Evento o sr(a) } \\
\text { observa a preocupação dos } \\
\text { realizadores com a } \\
\text { preservação do meio } \\
\text { ambiente? }\end{array}$ & $\begin{array}{l}\text { Identificar ações de } \\
\text { preservação ambiental e } \\
\text { conscientização do } \\
\text { público }\end{array}$ & $\begin{array}{l}\text { A divulgação do Bioma Cerrado } \\
\text { durante o Evento, oficinas de meio } \\
\text { ambiente e a realização do Evento no } \\
\text { Centro Histórico, representam para os } \\
\text { entrevistados essa preocupação. }\end{array}$ \\
\hline $\begin{array}{l}\text { Na sua opinião o FICA } \\
\text { representa a cidade e } \\
\text { contribui para sua } \\
\text { valorização? }\end{array}$ & $\begin{array}{l}\text { Verificar ações de } \\
\text { valorização da cultura } \\
\text { local }\end{array}$ & $\begin{array}{l}\text { Os respondentes acreditam que sim, } \\
\text { pois para eles o FICA representa a } \\
\text { cidade. }\end{array}$ \\
\hline $\begin{array}{l}\text { O sr(a) considera o FICA um } \\
\text { evento responsável } \\
\text { socioculturalmente, } \\
\text { economicamente e } \\
\text { ambientalmente? }\end{array}$ & $\begin{array}{l}\text { Aferir a percepção do } \\
\text { entrevistado sobre a } \\
\text { responsabilidade do } \\
\text { FICA. }\end{array}$ & $\begin{array}{l}\text { Essa questão divide opiniões pois } \\
\text { quase metade dos respondentes não } \\
\text { reconhecem a responsabilidade em } \\
\text { todas as dimensões. }\end{array}$ \\
\hline
\end{tabular}

responsabilidade é o seu público. Quanto a organização, apesar da responsabilidade não 
estar presente na intencionalidade do Evento, a temática ambiental acaba por direcionar ações de responsabilidade nesta dimensão e o amadurecimento da comunidade fez surgir projetos voltados para a integração da mesma ao Evento.

Desse modo o Quadro 2 demonstra um resumo dos aspectos observados no FICA 2016 de acordo com cada dimensão da responsabilidade analisada.

Quadro 2: Aspectos observados no FICA 2016

\begin{tabular}{|c|c|c|}
\hline Dimensão & Aspectos positivos & Aspectos a melhorar \\
\hline Sociocultural & $\begin{array}{l}\text { A comunidade é envolvida em diversos } \\
\text { projetos. Esses projetos acontecem no } \\
\text { Evento e também durante o ano através de } \\
\text { oficinas com os alunos da rede pública, por } \\
\text { exemplo. Além do envolvimento da } \\
\text { comunidade, houve frutos do FICA como a } \\
\text { faculdade de cinema. }\end{array}$ & $\begin{array}{l}\text { Há críticas severas de } \\
\text { moradores que não } \\
\text { concordam que o Evento } \\
\text { traga benefícios a longo } \\
\text { prazo, apenas } \\
\text { momentâneos. } \\
\text { A história da Cidade é pouco } \\
\text { divulgada pelo Evento. }\end{array}$ \\
\hline Econômica & $\begin{array}{l}\text { Gera empregos na Cidade, mesmo } \\
\text { temporários. Há certo aquecimento da } \\
\text { economia devido ao fluxo de turistas. } \\
\text { Promove visibilidade da cidade podendo } \\
\text { atrair outros públicos. }\end{array}$ & $\begin{array}{l}\text { Há pouca divulgação da } \\
\text { cultura e artesanato regional } \\
\text { por parte do Evento. }\end{array}$ \\
\hline Ambiental & $\begin{array}{l}\text { O meio ambiente enquanto temática gera } \\
\text { diversas ações que promovem } \\
\text { conscientização e discutem sua } \\
\text { preservação inclusive envolvendo a } \\
\text { comunidade nessas atividades. A } \\
\text { infraestrutura utiliza de vários espaços } \\
\text { abertos diminuindo consumo de energia, há } \\
\text { ações voltadas a coleta do lixo. }\end{array}$ & $\begin{array}{l}\text { Aumento do fluxo de carros } \\
\text { sem projetos de } \\
\text { compensação de emissão } \\
\text { de carbono. }\end{array}$ \\
\hline
\end{tabular}

Fonte: Elaborado pelas autoras

Desse modo, percebe-se que o FICA 2016 possui diversos acertos quanto a responsabilidade de modo que, inserindo-a desde o seu planejamento, é possível realizar um Evento que atenda as dimensões da responsabilidade de modo completo. No entanto, analisando o FICA 2016 constata-se que há aspectos que podem ser melhorados na inclusão da responsabilidade na sua realização.

Analisando a responsabilidade no FICA 2016 nota-se que o Evento utiliza-se da temática ambiental sem possuir ações voltadas para essa questão. Apesar do FICA Limpo, dos Fóruns de meio ambiente e da própria temática do Festival e dos filmes nele apresentados chamarem atenção para práticas que sejam ambientalmente sustentáveis, não se identifica no Evento ações significativas nesse sentido.

O FICA Limpo se torna insuficiente diante da produção de lixo gerada durante o Evento. Os fóruns possuem público pequeno ou quase inexistente, não obtendo assim um alcance significativo. Por possuir temática ambiental, o Evento deveria trabalhar de modo a se tornar uma referência em ER e para isso utilizar dos acertos que possui, apesar deles parecerem ser obra de mera coincidência e acaso. 
Realizar um Evento que contemple todos os aspectos de responsabilidade pode parecer algo intangível, no entanto esse não deve ser motivo para não considerar a sua realização. Deve-se buscar a responsabilidade em todas as etapas, direcionando as práticas para este foco, envolvendo a comunidade, promovendo sua integração, a conscientização e a preservação ambiental, valorizando a cultura e respeitando as individualidades de cada localidade.

\section{Entrevistas com gestores/organizadores do FICA 2016}

As entrevistas com gestores/organizadores tinham como principal objetivo captar a intencionalidade do Evento. Saber se a sustentabilidade era peça central de seu planejamento ou apenas integrante de sua temática. Também foram realizadas entrevistas com pessoas que faziam parte da organização e/ou trabalhavam no FICA durante sua realização. Ao todo foram entrevistadas 4 pessoas.

Com base nas entrevistas foi possível identificar que a inspiração para a criação do FICA veio da participação de um dos idealizadores no CineEco que ocorre em Portugal. Este Evento, por sua vez, se trada do Festival Internacional de Cinema e Vídeo de Ambiente da Serra da Estrela que teve sua primeira edição no ano de 1995 (CineEco), ou seja, quatro anos antes da primeira edição do FICA que ocorreu em 1999.

A preocupação com a responsabilidade, principalmente na dimensão ambiental, é percebida na temática. Apesar de assim ficar implícito, é possível notar que ela é exclusivamente tema do Evento, e não necessariamente elemento considerado na elaboração do planejamento que diz respeito a ações práticas. Isso fica ainda mais evidente na fala que segue: "Aí o ano de 2002 foi definitivo pro FICA. Marconi ganhou novamente a eleição e eu o convenci a deixar o FICA só na área de cultura porque ele era um FESTIVAL DE CINEMA, meio ambiente era só uma temática" (Organizador 1)

Essa fala é recorrente e um segundo interlocutor, quando questionado também sobre as ações de sustentabilidade do Evento, afirma que:

O FICA é um FESTIVAL DE CINEMA. Ele tem esse nome de Festival de Cinema e Vídeo Ambiental mas a parte ambiental a gente ainda engatinha um pouco, infelizmente. Ele é um festival de cinema com temática ambiental. A ideia hoje é transformar ele num festival ambiental e de cinema. Mas ele ainda é um festival de cinema. (Organizador 2)

Como resumo das percepções e análise das entrevistas realizadas com os gestores do FICA, apresenta-se o Quadro 3 a seguir. 
Quadro 3: Análise das entrevistas com gestores/organizadores

\begin{tabular}{|c|c|c|}
\hline \multicolumn{3}{|c|}{ Roteiro de Entrevista com Gestores/ Organizadores } \\
\hline Questão norteadora & Objetivo & Percepção e análise \\
\hline $\begin{array}{l}\text { Como foi concebido } \\
\text { o FICA? Qual é o } \\
\text { objetivo do Evento? }\end{array}$ & $\begin{array}{l}\text { Identificar a } \\
\text { preocupação com a } \\
\text { responsabilidade } \\
\text { desde a concepção do } \\
\text { Evento. }\end{array}$ & $\begin{array}{l}\text { Para os entrevistados o Evento se trata de um } \\
\text { Festival de Cinema e não um evento ambiental ou } \\
\text { responsável. Isso está presente somente na } \\
\text { temática do Evento, mas não é seu propósito } \\
\text { promover esse aspecto, mas sim o cinema. }\end{array}$ \\
\hline $\begin{array}{l}\text { Por que a cidade de } \\
\text { Goiás foi escolhida } \\
\text { para a realização do } \\
\text { Evento? }\end{array}$ & $\begin{array}{l}\text { Verificar a } \\
\text { preocupação com a } \\
\text { valorização da cultura, } \\
\text { desenvolvimento local. }\end{array}$ & $\begin{array}{l}\text { A escolha da cidade foi feita no contexto de } \\
\text { tombamento como Patrimônio. Para isso era } \\
\text { necessário inserí-la no contexto internacional e a } \\
\text { proposta do Evento foi ao encontro dessa } \\
\text { necessidade. }\end{array}$ \\
\hline $\begin{array}{l}\text { Como é realizada a } \\
\text { escolha de } \\
\text { fornecedores? }\end{array}$ & $\begin{array}{l}\text { Verificar se há } \\
\text { preocupação com a } \\
\text { sustentabilidade, } \\
\text { contratação de } \\
\text { fornecedores locais. }\end{array}$ & $\begin{array}{l}\text { Nos primeiros anos foi difícil trabalhar com } \\
\text { fornecedores locais devido a informalidade. Mas } \\
\text { com o passar dos anos esse cenário se modificou } \\
\text { e no contexto atual busca-se trabalhar com } \\
\text { fornecedores locais. }\end{array}$ \\
\hline $\begin{array}{l}\text { Como é realizada a } \\
\text { contratação de } \\
\text { pessoas para } \\
\text { trabalharem no } \\
\text { Evento? }\end{array}$ & $\begin{array}{l}\text { Identificar se são } \\
\text { contratadas pessoas } \\
\text { da comunidade e } \\
\text { como se dá esse } \\
\text { processo de modo a } \\
\text { promover valorização } \\
\text { da economia local } \\
\text { através de espaço } \\
\text { para participarem com } \\
\text { produtos locais e } \\
\text { criação de empregos } \\
\text { locais. Em caso } \\
\text { negativo identificar o } \\
\text { motivo. }\end{array}$ & $\begin{array}{l}\text { Nas primeiras edições a mão de obra era trazida } \\
\text { de Goiânia, com o passar dos anos a própria } \\
\text { comunidade exigiu sua participação e atualmente } \\
\text { é realizada a contratação de mão de obra local. }\end{array}$ \\
\hline $\begin{array}{l}\text { Como a comunidade } \\
\text { local participa do } \\
\text { Evento? Existe } \\
\text { contribuição por } \\
\text { parte do Evento para } \\
\text { projetos sociais } \\
\text { locais, trabalhos com } \\
\text { a comunidade? }\end{array}$ & $\begin{array}{l}\text { Verificar a inclusão da } \\
\text { comunidade local e } \\
\text { valorização da } \\
\text { mesma. }\end{array}$ & $\begin{array}{l}\text { A participação da comunidade ocorre } \\
\text { principalmente pelo envolvimento em projetos } \\
\text { como o FICA Limpo, FICA na Comunidade, Se } \\
\text { Liga no FICA que promovem a valorização da } \\
\text { cultura local, incentivo a artistas locais, integram } \\
\text { os moradores no planejamento do Evento e } \\
\text { atividades voltadas às crianças da rede pública } \\
\text { de ensino. Além disso há participação de } \\
\text { moradores nas atividades oferecidas pelo Evento } \\
\text { como as exibições dos filmes. }\end{array}$ \\
\hline $\begin{array}{l}\text { Quais são as ações } \\
\text { de educação } \\
\text { ambiental que são } \\
\text { realizadas durante o } \\
\text { Evento (para } \\
\text { alcançar o } \\
\text { participante)? }\end{array}$ & $\begin{array}{l}\text { Verificar ações de } \\
\text { educação ambiental }\end{array}$ & $\begin{array}{l}\text { Presente principalmente na temática e } \\
\text { programação do Evento, no entanto o foco ainda } \\
\text { é a realização de um festival de cinema. }\end{array}$ \\
\hline $\begin{array}{l}\text { Como é realizada a } \\
\text { gestão de resíduos } \\
\text { do Evento? Quais } \\
\text { ações (coleta } \\
\text { seletiva, parceria } \\
\text { com cooperativas) } \\
\text { são tomadas em } \\
\text { relação a isso? }\end{array}$ & $\begin{array}{l}\text { Identificar ações de } \\
\text { proteção ambiental }\end{array}$ & $\begin{array}{l}\text { O FICA Limpo é a ação mais expressiva nesse } \\
\text { sentido pois a estrutura da cidade tem dificuldade } \\
\text { quanto a coleta do lixo, o que se agravava no } \\
\text { período do Evento. Desse modo essa ação busca } \\
\text { uma alternativa e dar um suporte a estrutura de } \\
\text { coleta de lixo da cidade. }\end{array}$ \\
\hline $\begin{array}{l}\text { O senhor já ouviu } \\
\text { falar em Eventos }\end{array}$ & $\begin{array}{l}\text { Verificar se existe } \\
\text { conhecimento sobre o }\end{array}$ & $\begin{array}{l}\text { Ao mencionar os EV, EN e ER os interlocutores } \\
\text { demonstram um conhecimento superficial e }\end{array}$ \\
\hline
\end{tabular}




\begin{tabular}{|c|c|c|}
\hline $\begin{array}{l}\text { Verdes (EV) ou } \\
\text { Eventos Neutros } \\
\text { (EN)? }\end{array}$ & $\begin{array}{l}\text { assunto e como isso } \\
\text { ocorre na prática no } \\
\text { evento em questão. }\end{array}$ & $\begin{array}{l}\text { tornam a afirmar que o foco do Evento é o } \\
\text { Cinema e não a responsabilidade. }\end{array}$ \\
\hline $\begin{array}{l}\text { O FICA busca ser } \\
\text { um evento } \\
\text { responsável? Como } \\
\text { isso acontece na } \\
\text { prática? }\end{array}$ & $\begin{array}{l}\text { Verificar a } \\
\text { compreensão da } \\
\text { responsabilidade em } \\
\text { eventos e práticas que } \\
\text { possam não ter sido } \\
\text { exploradas até então. }\end{array}$ & $\begin{array}{l}\text { O foco do Evento é o Cinema. As ações tem a } \\
\text { sustentabilidade como temática, porém o Evento } \\
\text { não é concebido na lógica da sustentabilidade. } \\
\text { De qualquer modo, devido a temática, ações } \\
\text { responsáveis são praticadas. }\end{array}$ \\
\hline
\end{tabular}

Fonte: Elaborado pelas autoras

Nas entrevistas identifica-se que na etapa de criação, o Evento é concebido exclusivamente como um festival de cinema que contém na sua temática as questões ambientais, no entanto não se trata de um Evento que se preocupa em ser responsável. Torná-lo portanto um ER é uma preocupação presente na fala dos entrevistados, mas não há uma ação efetiva e definida para cumprir esse objetivo e assim o realizar desde o seu planejamento até sua execução.

Pode-se fazer a relação no tocante a temática ambiental devido a visibilidade que ela traz, chamando assim a atenção para o Evento. Como afirmam Fonseca e Bursztyn (2007) poderia essa ser uma evidência de que o Evento toma carona na visibilidade e importância que a temática possui, sem de fato se preocupar com a responsabilidade e suas ações sustentáveis.

No segundo bloco as questões tinham o objetivo de identificar ações de responsabilidade que o Evento pratica podendo assim assinalar práticas neste sentido. Foi possível identificar ações de responsabilidade que contemplassem o planejamento e execução do Evento. Foram identificadas ações pontuais referentes a escolha de fornecedores. Mas deve-se ressaltar que, com o passar das edições, o que foi destacado nas entrevistas realizadas foi o crescimento do envolvimento e participação da comunidade. Isso é expressado na criação de projetos que são respostas às exigências da comunidade como a criação do FICA Limpo que surge da preocupação dos moradores com o lixo na Cidade durante o período do Evento, como também o projeto FICA na Comunidade que inclui apresentações de artistas locais na programação valorizando e divulgando os artistas da região.

A aproximação com a comunidade escolar também é um ponto a ser destacado. Um dos entrevistados destaca essa ação e relata a sua importância:

Esse relacionamento com escola a gente sempre procurou. É difícil fazer a interface da Secretaria da Cultura com a Secretaria da Educação. Agora há a unificação dessas secretarias e agora virou missão. Na segunda edição do Festival já houve algumas oficinas de produção de filme. O Lázaro Ribeiro que é um cineasta vilaboense começou fazendo oficina na escola. $E$ é bacana ver isso, é o próprio Festival já dando fruto, já dando resultado. Fora a visibilidade que a gente consegue alcançar, as atrações que a gente consegue trazer pro pessoal da cidade. (Organizador 2) 
Apesar do envolvimento da comunidade ser o ponto forte até aqui observado no FICA, quando os entrevistados são questionados sobre EV, EN e ER a resposta é a reafirmação de que se trata de um evento relacionado ao cinema com temática ambiental. Portanto, seu foco é o cinema e não a responsabilidade. No entanto, a temática acaba por conduzir ações de responsabilidade dentro do Evento, o que pode ser observado no Quadro 2 apresentado.

Desse modo, é possível identificar ações de responsabilidade no Evento apesar de elas não serem realizadas de forma consciente e ordenada, mas em atividades que promovem o envolvimento e valorização da comunidade local onde o FICA demonstra ações de responsabilidade. Mesmo que não contemple todos os aspectos, ainda assim já existem ações de responsabilidade evidenciando e corroborando com a ideia de que a realização de ER é possível desde que essa premissa seja considerada desde sua concepção, o que, de fato, não realizado no caso específico do FICA.

\section{Considerações finais}

Com o objetivo de identificar a responsabilidade em eventos, foi escolhido o XVIII FICA 2016, um festival de cinema que ocorre na cidade de Goiás e que realizaria no ano em questão sua décima oitava edição. Por contemplar em seu nome a temática ambiental e se tratar de um Evento realizado em uma cidade considerada Patrimônio da Humanidade, ele foi escolhido para análise.

Foi possível constatar que, apesar de possuir em sua temática a questão ambiental, ele não se trata de um Evento que possui em sua concepção o objetivo de ser sustentável. No entanto, no decorrer das edições, essa preocupação foi surgindo e a responsabilidade foi sendo incorporada a projetos que hoje fazem parte do Evento como o FICA na Comunidade e o FICA Limpo.

Além disso, os fóruns ambientais e diversas outras atividades que fazem parte da sua programação discutem temáticas relacionadas a sustentabilidade, envolvem a comunidade local, proporcionam consciência e educação ambiental. Portanto, foi possível identificar ações de responsabilidade no Evento, apesar dele não ter sido planejado com esse enfoque desde a sua primeira edição.

O Evento se destaca no envolvimento da comunidade local, pois envolve a participação de escolas nas oficinas, traz educação ambiental e proporciona conhecimentos sobre cinema com oficinas fora do período do Evento, mas que fazem parte das atividades do mesmo. Promove o FICA Limpo que traz consciência e busca uma alternativa para a gestão do lixo. 
Portanto, é possível identificar ações de responsabilidade. Apesar da apropriação da temática no início parecer ser irresponsável, sendo utilizada apenas como modismo ou para promover o Evento, hoje ele já incorpora algumas ações de responsabilidade em suas práticas.

No entanto, conforme discutido no decorrer desse artigo, é importante considerar todos os aspectos para que um evento seja, de fato, responsável. Por esse motivo afirma-se que, apesar de possuir ações de responsabilidade, o FICA ainda não pode ser considerado um Evento Responsável. Para que isso se concretize, é necessário consolidar mais ações ambientais e de retorno econômico para a Cidade de Goiás. Problemas como questões relacionadas ao abastecimento de água na Cidade, a produção do lixo e a destinação que ele recebe, são aspectos que dever ser enfatizados e priorizados pelo Evento. No entanto, conforme relatos dos moradores, a preocupação com esses aspectos é pouca ou inexistente.

É possível perceber pelas entrevistas o amadurecimento do Evento em relação ao impacto gerado na Cidade e isso é evidenciado pelos projetos que foram surgindo, a preocupação com a contratação de pessoal da Cidade, os projetos de valorização e envolvimento da comunidade. Portanto, infere-se que todo Evento pode ser responsável, mas para que isso seja possível é necessário que essa preocupação esteja presente em todas as etapas, desde o planejamento, na execução e após o Evento.

\section{REFERÊNCIAS}

Bottallo, M. (2014). Patrimônio da Humanidade no Brasil: suas riquezas culturais e naturais / Heritage of Humanity in Brazil: cultural and natural riches. 1. ed. - Santos, SP: Editora Brasileira de Arte e Cultura: UNESCO Brasil. Recuperado de http://unesdoc.unesco.org/images/0023/002333/233395m.pdf

Cape Town, África do Sul. (2002). Cape Town Declaration in Responsible Tourism. Cape Town Conference on Responsible Tourism in Destinations. Cidade do Cabo. Recuperado de http://responsiblecapetown.co.za/tools/Document-Library/

Farias, F. S., Zucco, F. D. \& Falaster, C. D. (2019). Ampliar los horizontes Y conocer cosas nuevas: la imagen de eventos a partir de la perspectiva de los visitantes de la Fiesta de São João de Campina Grande - Paraíba, Brasil. Estudios y Perspectivas em Turismo. vol. 18, p. 331- 353.

Fonseca, I. F. \& Bursztyn, M. (2007). Mercadores de moralidade: a retórica ambientalista e a prática do desenvolvimento sustentável. Ambient. Soc., Campinas, v. 10, n. 2, p. 169-

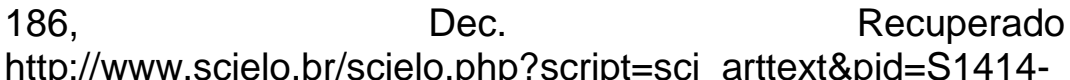

$753 \times 2007000200013 \&$ lng =en\&nrm=iso

Goodwin, H. (2012). Taking Responsibility for Tourism. ICRT.

Hardin, G. (1968). The tragedy of the commons. Science, n.162. 
Leslie, D. (2012). Responsible Tourism. Concepts, Theory and Practice. Oxfordshire, UK: CAB International.

Macedo, S. B., Gosling, M. S. \& Queiroz, D. C. (2017). Eventos Culturais : meu dinheiro me diz aonde eu vou ? Uma análise sob a ótica da Teoria da Identidade Social (SIT). Revista Hospitalidade. São Paulo, vol. 1, n. 01, p. 01-23, ago.

Matias, M. (2013). Organização de eventos: procedimentos e técnicas. 6ed. Barueri, SP: Manole.

Oliveira, M. M. (2007). Como fazer pesquisa qualitativa. Petrópolis, RJ: Vozes.

Pereira, G. S. \& Conto, S. M. (2008). Manejo de resíduos sólidos en un evento turístico: fiesta nacional de la uva (RS - Brasil). Estudios y Perspectivas em Turismo. vol. 17, p. 119- 139.

Ramoa, C. E. A., Flores, L. C. S. \& Stecker, B. (2018). The convergence of environmental sustainability and ocean cruises in two moments: in the academic research and corporate communication. Revista Brasileira de Pesquisa em Turismo. São Paulo, 12 (2), p. 152-178, maio/ago.

Silberberg, C. P. \& Dowll, D. M. (2010). Gestão Ambiental e Responsabilidade Social em Eventos. In: PHILIPPI JR., Arlindo; RUSCHMANN, Doris Van de Meene. Gestão ambiental e sustentabilidade no turismo. Barueri, SP: Manole. (Coleção Ambiental, v.9). 